Research Article

\title{
Knowledge and attitude towards the use of emergency contraceptive pills among college students
}

\author{
Prakash R. Shelat*, Nikunj H. Hihoriya, Shivaprasad Kumbar
}

Department of Pharmacology, B. J. Medical College, Ahmedabad 380016, India

Received: 9 September 2012

Revised: 20 September 2012

Accepted: 22 September 2012

\author{
*Correspondence to: \\ Dr. Prakash R. Shelat, \\ E-mail: \\ dr.prakashshelat@gmail.com
}

\begin{abstract}
Background: Emergency contraception is applied to prevent pregnancy after 72-120 hours of unprotected sexual intercourse. Emergency contraceptive (EC) pill is used to reduce unwanted pregnancy and unsafe abortion. EC pill is available as OTC in India since 2005. As EC pill highly used among adolescents we carried out to this study among college students.

Methods: The study was conducted among female college students. A prevalidated questionnaire was used as tool for the study. It contains consent form and questions knowledge and attitude regarding EC pill.

Results: We divided students into group A (medical, paramedical and pharmacy colleges) and group B (nonmedical colleges like science, arts and engineering). In group A 470 and group B 280 students were participated. Knowledge about appropriate time of taking EC pill (within 72 hours after sexual intercourse) was $44 \%$ in group A which is significant than $15 \%$ in group B. Knowledge about brand name, availability cost and side effects were more in group A than group B. Electronic media was the most common source of information mentioned by both the groups. Attitude regarding advice to use of EC pill to other was more in group A than group B.

Conclusions: Knowledge about use of EC pill was higher in group A than group B. Attitude was not positive regarding availability of EC pill as OTC. So education about EC pill among young population is necessary.
\end{abstract}

Keywords: Emergency contraception (EC), Emergency contraception pill (ECP), Female students

\section{INTRODUCTION}

Overpopulation in India is the burning problem which is a major cause of poverty, illiteracy, decrease economy growth, starvation, malnutrition, depletion natural resources. ${ }^{1}$ In India, $78 \%$ of the pregnancies are unplanned and at least $25 \%$ are unwanted. Every year 11 million abortions take place and at least half of these are unsafe and associated with a high morbidity and mortality. At least 20,000 women are dying annually due to abortion related complications., ${ }^{2,3}$

Emergency contraception is one of the methods to prevent unplanned and unwanted pregnancy. ${ }^{4}$ The Emergency contraceptive (EC) pill has been approval as over thecounter (OTC) by Government of India since $2005 .^{5}$ Its availability as OTC drug had led to misuse and improper use of EC pills. There are no parallel educational programs to the community to give knowledge about EC pill. Moreover, no proper instructions are given to users by pharmacist at chemist shop. Hence, users are unaware about its method of use, time of administration and adverse effects etc. ${ }^{6}$ This product was approved as an OTC product to reduce the rates of unwanted pregnancy and unsafe abortion but the fear of its use and improper use has failed to achieve the objective.

Emergency contraception is commonly used by adolescent girls and young married women. ${ }^{7}$ It has been reported from Northern India that there is little knowledge regarding indications, availability and time of use of emergency contraception among college students. ${ }^{8}$ Young college girls are the prospective users of EC pills.

Moreover, no survey yet has been done regarding knowledge of the use of EC pill in young college girls in western part of India. Hence, this study was conducted to investigate the knowledge and attitude towards the use of EC pill in different medical and nonmedical college girls in the city of Ahmedabad. 


\section{METHODS}

Out of the total 260 colleges (including medical and nonmedical) present in Ahmedabad city, 16 colleges of arts, commerce and science were randomly selected on the basis of varied education for the study. Students were divided into group A (medical and paramedical colleges) and group B (including arts, science, engineering colleges). All the colleges were approached and permission was taken from the Principal to conduct the study. We were included first year to final year students according to their availability in colleges after permission. A preformed validated structural questionnaire (Annexure 1) was used to evaluate knowledge and attitude towards use of emergency contraceptive pill. The participants were explained and written informed consent was obtained. Data was collected and analyzed by using SPSS version 18 .

\section{RESULTS}

The present study was carried out to know the knowledge of EC pills in young college girls. Out of 260, 16 colleges were approached. Students were divided into group A including medical and paramedical colleges and group B including arts, commerce, science and engineering colleges. Group A included 470 female students, out of which 165 students were from medical, 180 from paramedical (physiotherapy and nursing) 125 from pharmacy colleges whereas in group B 280 students were included out of which 140 were engineering students, 45 commerce students, 55 arts students and 40 science students. It was observed that the mean age of students in group A was $18 \pm 1.42$ years and in group B was $19 \pm 1.17$ years. Analysis of marital status revealed that 10 students were married in group A while all the students in group B were unmarried. It was observed that $86 \%$ students in group A and $46 \%$ students in group B had awareness about what an emergency contraception and this difference was significant $(p<0.001$, Table 1$)$.

It was observed that TV/ Radio was the most common source in both the groups $(71 \%$ in group A and $55 \%$ in group B) followed by newspaper / magazine. The other sources mentioned were doctor / nurse / pharmacist and friend / family. As observed from figure 1, knowledge about other aspects of using emergency contraceptive pill was significantly $(p<0.001)$ higher in group $\mathrm{A}$ as compared to group B.

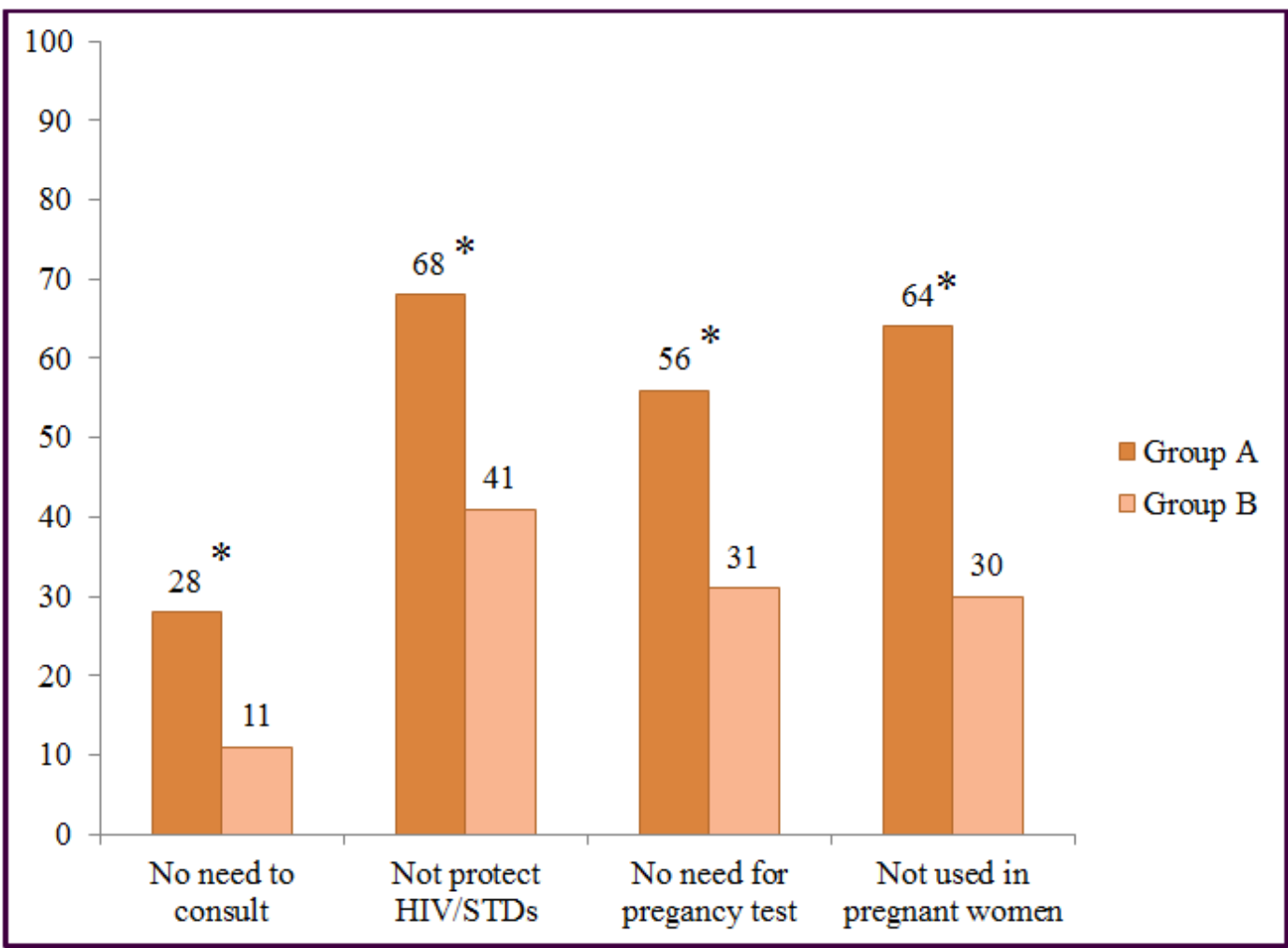

Figure 1: Analysis of knowledge about precaution of EC pill. $* p<0.001$ significantly higher as compared to group B 
Table 1: Analysis of knowledge of EC pill.

\begin{tabular}{|lll|}
\hline Knowledge & Group A $(\mathbf{n}=470)$ & Group B $(\mathbf{n}=\mathbf{2 8 0})$ \\
& $(\%)$ & $(\%)$ \\
Awareness & $86^{* *}$ & 46 \\
Brand name & $46^{* *}$ & 21 \\
Availability from pharmacy store & $71 * *$ & 37 \\
Cost (50-100 Rs) & $9 *$ & 4 \\
Appropriate time of taking & $44^{* *}$ & 15 \\
(within 72 hours after intercourse) & & 19 \\
No of tablet taking (1 tablet) & $38^{* *}$ & 13 \\
Side effects: Nausea/Vomiting & $44^{* *}$ & 21 \\
\multicolumn{1}{|c|}{ Menstrual irregularity } & $53 * *$ & 2 \\
Next menstrual period after taking tablet & $19 * *$ & 34 \\
Beneficial against unwanted pregnancy & $57 * *$ & \\
\hline
\end{tabular}

$* p<0.05, * * p<0.001$ significantly different as compared to group A

Table 2: Analysis of attitude against EC pill.

\begin{tabular}{|lll|}
\hline Attitude & $\begin{array}{l}\text { Group A } \\
(\%)\end{array}$ & $\begin{array}{l}\text { Group B } \\
(\%)\end{array}$ \\
Use of pill in unwanted pregnancy & 63 & 31 \\
Advice to others of its use & 46 & 33 \\
Available freely (without any advice) & 15 & 4 \\
\hline
\end{tabular}

It was observed that $19 \%$ students from group A and $2 \%$ student from group B had knowledge that they should expect their next period in 3 weeks after taking the tablet. $57 \%$ student from group A and $34 \%$ students from group $\mathrm{B}$ mentioned that emergency pill is beneficial and out of them $37 \%$ from group A and 13\% from group B also mentioned the reason about beneficial effects emergency pill. The most common reason mentioned by both group was to avoid unwanted pregnancy. Other reasons were unprotected sex, rape and birth control etc. It was observed that $64 \%$ students from group A students and $33 \%$ students from group B mentioned that emergency pill is not used as regular method of birth control measure.

The attitude of the students about the use of emergency pill was also assessed. It was observed that $63 \%$ students from group A and $31 \%$ students from group B were in favor of using emergency pill to avoid unwanted pregnancy and this difference in groups was statistically significant $(p<0.001)$. It was also observed that $46 \%$ students from group A and 33\% students from group B were in the favor to advice others about use of emergency pill and this different was also statistically significant $(p<$ 0.001 ). According to $15 \%$ students from group A and $4 \%$ students from group B were of attitude that emergency pill should be available freely without any advice and out of them 5\% group A students and $2 \%$ group B students also mentioned the reason for free availability of emergency contraceptive pill (Table 2).

\section{DISCUSSION}

The family planning program was launched in India 1952 with the objective of reducing birth rate. ${ }^{9}$ Temporary (e.g. Oral contraceptive pills, condom, IUCD, hormonal injections) and permanent methods (like tubectomy, vasectomy) of contraception have been introduced by family welfare department of India. $^{2}$ However unprotected, unplanned exposure and contraceptive accidents like forgotten pills, condom burst and slipping of diaphragm lead to failure of contraception and unwanted pregnancy which was lead to high abortion rate. ${ }^{6}$ Emergency contraception or postcoital contraception prevents unwanted pregnancy after unprotected sexual intercourse and failure of regular 
contraception. ${ }^{10}$ Hence this study was conducted to evaluate the knowledge and attitude towards the use of Emergency Contraceptive pill (newly introduced method of contraception for emergency use) in young female college students.

In our study we approached 13 colleges out of which only 5 heads of colleges agreed to conduct the survey. In our study it was observed that the knowledge about brand name and method of use was poor, in less than $50 \%$ students in group A, even though they had medical, paramedical and pharmacy background. A similar study done in private medical practitioner of Nigeria show that it was $60 \% .^{11}$ This shows that the knowledge about brand name and method of use in young female college students in India is poor though they had medical/paramedical background.

Knowledge about method of use (within 72 hours after unprotected sexual intercourse) in group A was $44 \%$ and was lower compare to similar study conducted in Delhi Medical Officers where it was 54\%. ${ }^{12}$ This knowledge in group B was $15 \%$ which was similar to a study in college students of Chandigarh but lower compare to group A. ${ }^{13}$ This shown that the knowledge about the use of emergency contraceptive pill is poor in Indian female college going students. Hence unawareness about proper method of use of this pill can not only lead to unwanted pregnancy but also may create health hazards.

Most of students got information of emergency contraceptive pill from electronic media in both groups in our study which was similar to a study in women at Chandigarh. ${ }^{14}$ But report of study at Sikkim in nursing students and at Karachi in working women that they got information from health care professionals. ${ }^{5,15}$ A study at Cameron shows that the most common source of information mentioned friend/family. ${ }^{16}$ Thus, different countries use different source of information regarding emergency pill. However this source of information is commercial and hence may be associated with misinformation. Hence a more unbiased and noncommercial source could educate the students completely about emergency contraceptive pill.

The knowledge about its availability at pharmacy store in group A $(71 \%)$ was similar to study in private medical practitioner $(73 \%)$ at Nigeria. ${ }^{11}$ The knowledge about ADR was more than $40 \%$ students in group A whereas a study at New Delhi done on health care staff was $47 \%{ }^{7}$ However this knowledge was $13 \%$ in group B which was higher compare to $4 \%$ in university students in Chandigarh. ${ }^{13}$ This shows that the knowledge about ADR is poor in general population. This is important as incomplete knowledge about ADR can lead to its injudicious use. The students were aware about emergency contraceptive pill not protecting against HIV and STDs.
The attitude to advice others regarding the use emergency contraceptive pill was high in group A (46\%) as compared to group B (33\%). While both group A and group B students believed that it should be available with doctor/ pharmacist advice similar to a report in Karachi. ${ }^{15}$ This shows that the student are not in favor of its availability as an OTC. The possible reason may be its misuse by younger generation and hence would encourage unsafe sexual relationship. The availability with prescription would help to have more reliable and wanted contraception. It is emphasized that there is need to educate the general population specially the young female population about the use of emergency contraceptive pill. Family planning clinics, articles in newspaper and magazine can be used as method of education about the method of use of emergency contraceptive pill.

There are few limitations in our study. As the study is done on sensitive issue like contraception all the head/principal of the colleges did not agree and hence we could not include more students in the study. The practice part could not be covered as it was a personal issue for the students.

The knowledge about the use of emergency contraceptive pill is above $50 \%$ in medical/paramedical students. However, the knowledge in nonmedical students is poor. Electronic media being the most popular media can be used as a method to impact knowledge about its use and ADR. However the attitude towards the use of emergency contraceptive pill is not positive and hence advertisement through electronic media, education in college students by health care professionals can help in achieving the goal of reduction in unwanted child births.

\section{REFERENCES}

1. Park K. Park's Text Book of Preventive and Social Medicine. 18th ed. Jabalpur: M/S Banarasi Das Bhanot; 2005:361.

2. Mehra R, Goel P, Dua D, Huria A. Knowledge of emergency contraception among women coming for induced abortion. J Obstet Gynecol India 2006;56:233-5.

3. International Institute for Population Sciences (IIPS) and Macro International. National Family Health Survey (NFHS-3), 2005-06. Available at http://pdf.usaid.gov/pdf_docs/PNADK385.pdf. Accessed 6 June 2012.

4. Saikia H, Lama A. OTC-Availability of emergency contraceptive Levonorgestrel: A Review. J Pharm Res 2011;4:67-71.

5. Rahaman H, Renjhen P, Kumar A, Pattanshetty S, Sagir A, Dubey H. A study on Emergency Contraceptive practice among nursing staff in 
Sikkim, India- A cross sectional study. AMJ 2010;3:667-71.

6. Government of India. Guidelines for Administration of Emergency Contraceptive Pills by Health Care Providers. Family Planning Division, Ministry of Health and Family Welfare, Govt of India, Nov' 2008. Available at http://mohfw.nic.in/NRHM/FP/ECP_Book_Final.pd f. Accessed 7 June 2012.

7. Kishore V, Misro MM, Nandan D. Providers' knowledge, attitude and dispensing practices of EPills in government dispensaries of south district in Delhi, India. Indian J Community Med 2010;35:4651.

8. Harrington P, Shepherd M. Analysis of the movement of prescription drugs to over-the-counter status. J Manag Care Pharm 2002;8:499-508.

9. Reddy SR, Premarajan KC, Narayan A, Mishra AK. Rapid appraisal of knowledge, attitude and practices related to family planning methods among men within 5 year of married life. Indian J Prev Soc Med 2003;34:63-6.

10. Puri S, Goe N, Sehagal A, Walia D, Mangat C. Emergnecy contraception in women of slums in Northern India. J Fam Reprod Health 2009;3:77-82.

11. Okonofuva FE, Omoaghoja LO, Hammed AA, Osaze KK. A survey of the knowledge and practices of emergency contraception by private medical practitioners in Nigeria. J Chin Clin Med 2009;4:329.

12. Singh S, Mittal S, Anandalakshmy P, Goel V. Emergency contraception: knowledge and views of doctors in Delhi. Health Popul Perspect Issues 2002;25:45-54.

13. Puri S, Bhatia V, Swami HM, Singh A, Sehgal A, Kaur AP. Awareness of emergency contraception among female college students in Chandigarh, India. Indian J Med Sci 2007;61:338-46.

14. Takkar N, Goel P, Saha PK, Dua D. Contraceptive practices and awareness of emergency contraception in educated working women. Indian J Med Sci 2005;59:143-9.

15. Irfan F, Karim S, Hashmi S, Ali S, Ali SA. Knowledge of emergency contraception among women of childbearing age at a teaching hospital of Karachi. J Pak Med Assoc 2009;59:235-40.

16. Kongnyuy EJ , Ngassa P, Fomulu N, Wiysonge C, Kouam L, Doh A. A survey of knowledge, attitudes and practice of emergency contraception among university students in Cameroon. BMC Emerg Med 2007;7:7. 
ANNEXURE: 1

Student Information Sheet $\quad$ Serial No.

We, Dr. Prakash R. Shelat, Dr. Nikunj H. Hihoriya and Dr. Shivaprasad Kumbar, postgraduate student of Department of Pharmacology, B. J. Medical College, Ahmedabad want to conduct a study on "Knowledge and attitude towards the use of emergency contraceptive pills among college students".

The purpose of this study is research. Kindly spare your few minutes for filling up the given forms.

\section{Consent form}

Date:

I consent voluntarily to participate in the research project conducted by Dr. Prakash R. Shelat, Dr. Nikunj H. Hihoriya and Dr. Shivaprasad Kumbar from B. J. Medical College, Ahmedabad. I am informed that the study entitled "Knowledge and attitude towards the use of emergency contraceptive pills among college students" is an educational study and the data will be used for research purpose only. I am also informed that my identity will not be disclosed.

Signature

Name (Optional):

Name of the Institution:

Marital status: married / unmarried

Education: Professional course

Any other course

$$
\text { Professional course }
$$

Age:

Residential address:

$\square$ I year

$\square$ II year

$\square$ III year

Other

Any other course

$\square$ I year

$\square$ II year

$\square$ III year

Other 


\section{Questionnaire}

Instructions: Tick $(\sqrt{ })$ the correct statement.

Title: Knowledge and Attitude towards the Use of Emergency Contraceptive Pills among College Students.

1. Do you know about emergency contraception?

2. It is available in the market as (brand names)

3. How did you come to know about emergency pill?

$\square$ TV / Radio $\square$ Newspaper / Magazine $\square$ Doctor /Nurse / Pharmacist $\square$ Friend / Family

4. The appropriate time of taking emergency pill is __ hrs. $\square$ before $/ \square$ after sexual intercourse.

5. The pill can be obtained from,
Government hospital
Private hospital
Pharmacy store
Others

6. The approximate cost of pill Rs.

7. A woman can use emergency pill for,
Unprotected sex
Forced sex
$\square$ Rape
Birth control measures
Failure of birth control measure
To induction of abortion

8. Do you need to consult a doctor before using emergency pill?

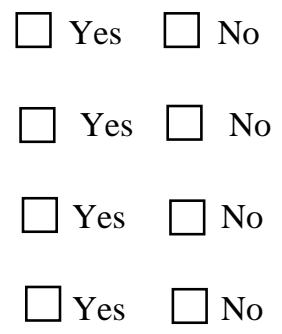

11. Is it effective if a woman is already pregnant?

12. Side effects of emergency pill are,
Nausea
Vomiting
Menstrual irregularity
Fever
Cough

13. The no. of tablets recommended for use is

$\square_{1} \square 2 \quad \square 3 \quad \square 4$

14. How frequently this pill can be repeated in a month/year?

$\square 1 \square 2 \square 3 \quad \square 4 \quad \square$ daily

15. A woman after taking emergency pill, should expect next period after weeks. 
16. Is emergency pill beneficial?

Yes $\square$ No If yes, mention the reason(s).

17. Can it be used regularly to avoid pregnancy? Yes $\square$ No If yes, mention the reason(s).

18. In your opinion, should this pill be used for unwanted pregnancy?

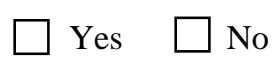

19. Will you recommend this pill to others?

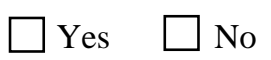

20. Should this pill be available?

$\square$ With doctor's advice

$\square$ With advice of pharmacist

Without any advice

Mention the reason(s). 